\title{
Implant hybrid prosthetic treatment in Down syndrome patient: a case report
}

\author{
Mi-Gyeong Kim, Jae-Hoon Kim, Ha-Rim Lee, Eun-Sun Jang, Hee-Jung Kim, Gyeong-Je Lee* \\ Department of Prosthodontics, School of Dentistry, Chosun University, Gwangju, Republic of Korea
}

Down syndrome patients generally have poor oral hygiene due to lack of awareness and ability to perform oral care, and there is a high risk of tooth loss. Also, they are characterized by small and irregular teeth and oligodontia, which makes it difficult to do prosthetic treatment. This article reports a case of implant hybrid prosthesis treatment of maxillary edentulous area in Down syndrome patient. The external shape of the final prosthesis was determined by using the mandibular artificial teeth to reflect the oligodontia of the mandible and the pontic areas were adjusted to facilitate oral hygiene care. As a result, aesthetically and functionally satisfactory results were obtained. (J Dent Rehabil Appl Sci 2018;34(3):225-31)

Key words: Down syndrome; oligodontia; implant hybrid prosthesis; prosthodontic maintenance

\begin{abstract}
서론
가장 흔한 염색체 이상으로 알려져 있는 다운 증후군 (Down syndrome) 환자는 21번 염색체가 3개로 과잉되 어 나타나는 질환으로 '21 삼염색체성 증후군'이라고도 불린다. ${ }^{1}$ 임상적 특징은 정신 지체, 짧은 신장, 단두증, 짧 고 넓은 목, 편평한 안면 등이 나타나며, 구강 내 특징은 거대설, 균열설, 균열된 입술, 좁은 구개, 부정교합, 선천 적 결손치, 유치와 영구치의 맹출 지연 등이 있다. ${ }^{2}$

환자의 유치는 정상인보다 큰 경향을 보이는 반면, 영 구치의 경우 상아질과 에나멜질이 얇아서 치아 크기가 작은 경향을 보이며 치주염의 빈도가 높다. Oliveira 등 ${ }^{3}$ 의 연구에 따르면, 치아 이상을 가진 환자들이 조사한 다 운증후군 환자 전체 중 $44 \%$ 비율을 차지하였고, 그 특징 으로 선천적 결손, 왜소치, 치근의 지연 형성, 법랑질 저형 성증, 융합 등이 있었다. Desai과 Flanagan ${ }^{4}$ 은 선천적 결
\end{abstract}

*Correspondence to: Gyeong-Je Lee

Assistant Professor, Department of Prosthodontics, School of Dentistry, Chosun University, 303, Pilmun-daero, Dong-gu, Gwangju, 61452, Republic of Korea Tel: +82-62-220-3827, Fax: +82-62-223-7776, E-mail: Ikj1998@chosun.ac.kr Received: May 30, 2018/Last Revision: July 4, 2018/Accepted: July 23, 2018
손의 영향을 가장 많이 받는 치아로 하악 전치, 상악 측 절치, 상하악 제2소구치, 대구치 순이라고 하였다. 또한 면역기능 저하로 인해 치주염의 이환율이 높고, 이로 인 해 치아 상실이 흔하게 관찰된다.

다운증후군 환자는 작고 불규칙적인 치아나 부분 무치 증으로 인해 심미적인 보철물 제작이 어렵고, 지능 저하 와 행동 장애가 동반되어 환자의 협조도가 낮아 보철물 의 유지관리 또는 구강위생관리가 어렵다. 이로 인해 환 자를 치료하기에 앞서 환자가 가지는 특성과 보철물 유 지관리를 고려하여 보다 신중한 치료 계획이 수립되어야 한다.

본 증례는 상악이 무치악인 다운증후군 환자를 대상으 로 제작한 임플란트 하이브리드 보철물로 최종 치료 진 행하였으며, 치료 후 심미적, 기능적으로 만족스러운 결 과를 얻었기에 이를 보고하고자 한다.

Copyright@ 2018 The Korean Academy of Stomatognathic Function and Occlusion. (c) It is identical to Creative Commons Non-Commercial License. 


\section{증례보고}

본 증례의 환자는 만 38세 여환으로 지대치 동요도를 주소로 본원에 내원하였다. 초진 시 상악은 6년 전 제작 한 탄성의치를 장착하고 있었고, 방사선 및 구내 검사 결 과로 잔존치는 동요도로 모두 발거가 필요하였으며, 하 악은 왜소치 및 전치부 상실이 관찰되었다(Fig. 1). 초기

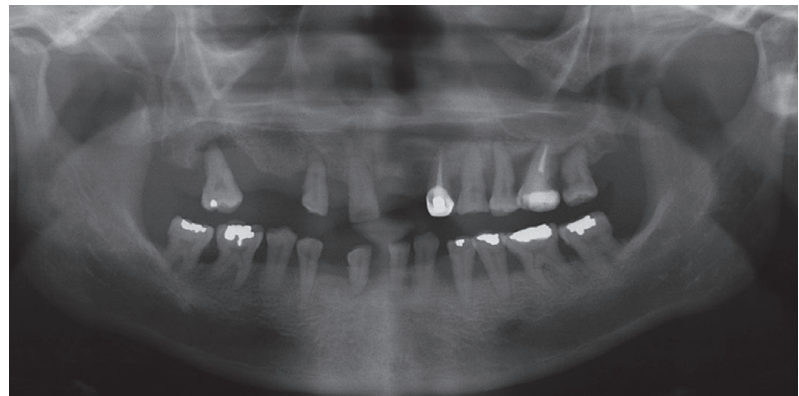

Fig. 1. Panoramic radiogragh at first visit.
치료계획으로 상악은 총의치를 제작하기로 하였다(Fig. 2). 첫번째 총의치는 하악 치열을 고려하지 않고 상악 인 공치를 이용하여 통상적인 방법으로 제작하였으나, 상 악은 일반 성인의 치열을, 하악은 다운증후군 환자의 치 열을 갖고 있어 상하악 치아의 조화로움이 떨어졌다(Fig. 3). 그리하여 환자, 보호자와 상의 후 하악 인공치를 이용 하여, 반대측 부분무치증의 치열과 자연스럽게 치아 배 열을 한 두 번째 총의치를 제작하였다(Fig. 4).

3 개월 간의 총의치 정기검진 기간 동안 의치의 유지력 저하와 환자의 구강 위생관리 미흡이 관찰되었고, 특히 환자와 보호자의 착탈 거부감으로 최종 치료 계획을 총 의치에서 임플란트 하이브리드 고정성 보철수복으로 변 경하였다.

임플란트 수술을 위하여 기존 총의치를 복제하여 컴퓨 터 단층촬영(Computed Tomography)을 위한 진단용 스 텐트를 제작, CT 촬영하였다. CT상에서 식립부위 골양 과 위치 평가하였고, \#16,14,12,22,24,26 부위에 임플란 트(TSIII, Osstem, Seoul, Korea)를 식립하였다(Fig. 5, 6).

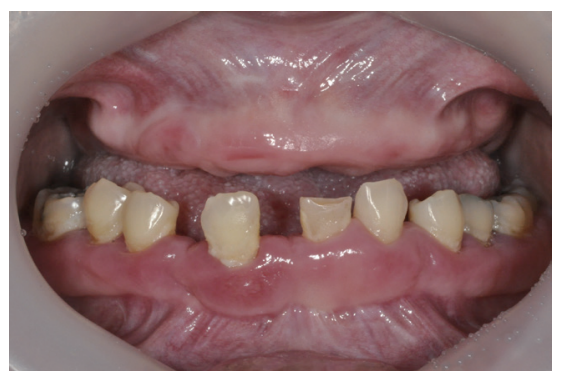

Fig. 2. Intraoral view after extraction of all residual teeth of maxilla.

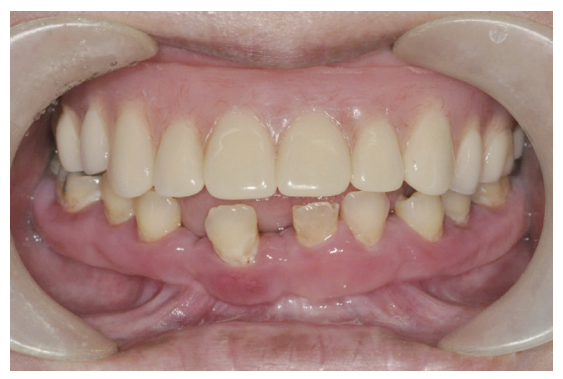

Fig. 3. Maxillary conventional complete denture.

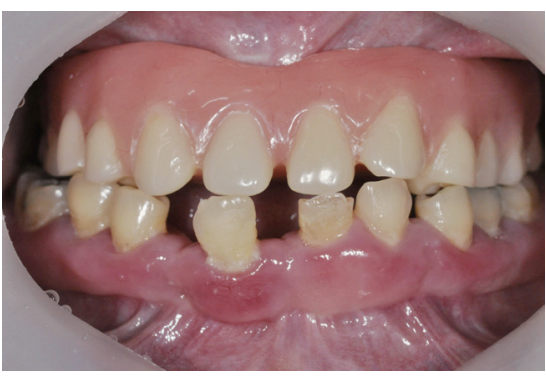

Fig. 4. Maxillary modified conventional complete denture.

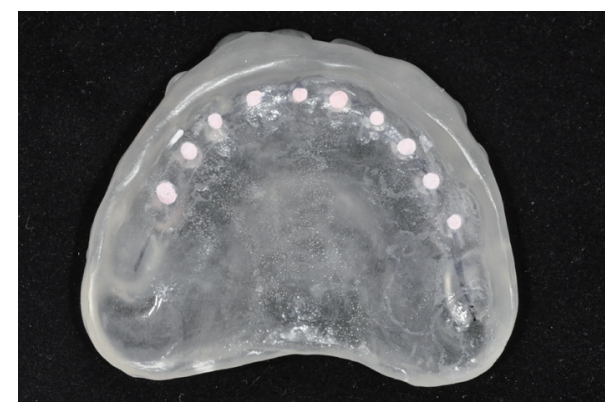

Fig. 5. CT stent made by duplication of complete denture.

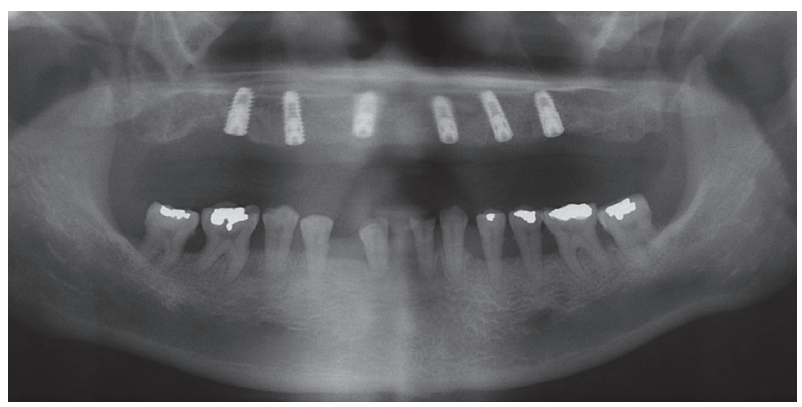

Fig. 6. Panoramic radiograph after implant surgery. 
6개월의 치유 및 골유착 확인 후 자가중합형 레진(Duralay, Reliance Dental Mfg Co., Alsip, USA)을 이용한 고 정 및 pick up 인상채득을 하여 임플란트 인상의 정확도 를 높였다(Fig. 7).

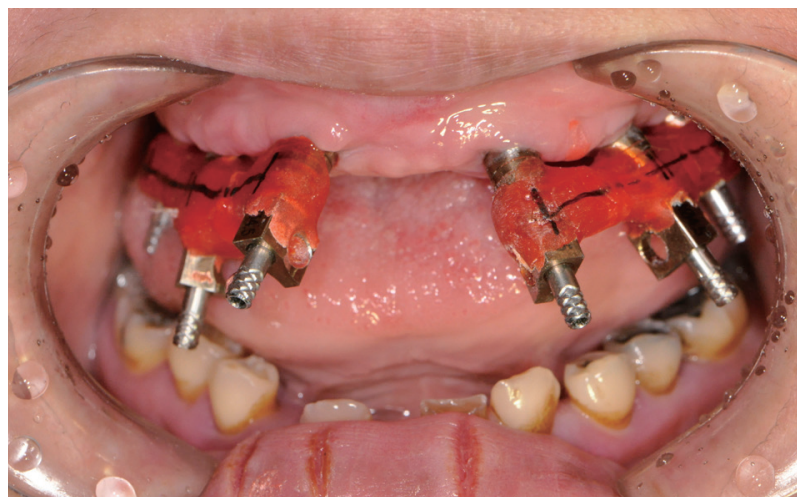

Fig. 7. Pick-up impression taking.
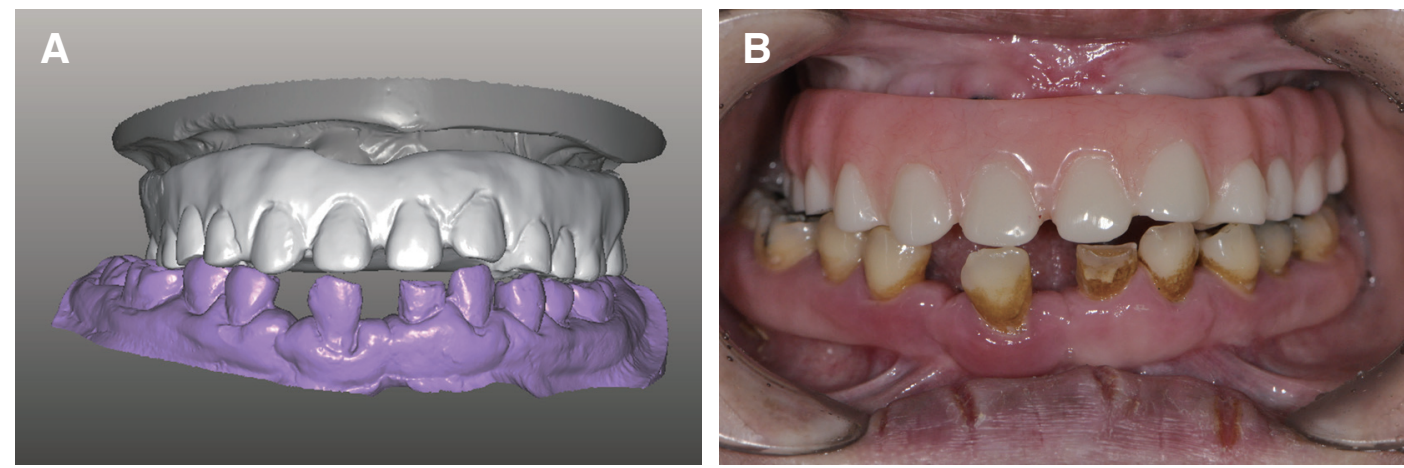

Fig. 8. Temporary crown was fabricated with scan data of old denture. (A) Old denture model scan image, (B) Temporary crown.

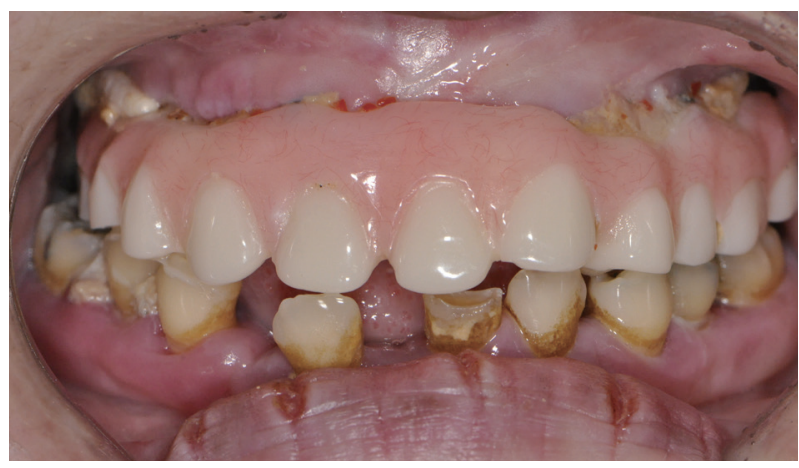

Fig. 9. Food retention around the temporary crown.
레진 기록상과 교합제를 이용하여 교합수직고경을 결 정하고 교합간 중심위를 채득하였으며, 안궁이전 후 반 조절성 교합기에 모형을 부착하였다. 기존 총의치를 모 델 스캔하여 Computer Aided Design (CAD)상에서 cut-back하고 밀링하여 맞춤형 지대주(Arun, Doowonid Co., Daejeon, Korea)와 임시치관(Easymill Resin, High Dental Korea, Seoul, Korea)을 제작하였다(Fig. 8). 임 시치관 장착 후 총의치 사용 중 치태관리가 미흡했던 것 처럼 이번에도 임시치관과 조직 사이에 음식물 저류가 관찰되었다(Fig. 9). 이에 치태관리가 용이할 수 있도록 임시치관의 가공치 부위를 상악 전치부는 변형된 치조 제 피개형(Modified ridge lap type)을, 구치부는 위생형 (hygienic type)으로 수정하였다(Fig. 10). 수정된 임시치 관으로 약 2 개월동안 구강위생관리 능력을 평가한 후 최 종 보철물 제작을 위해 기존의 안정된 수직고경을 이용 한 임시 치관을 절반으로 커팅하여 반대교합으로 바이트 채득 및 지대주 레벨 인상을 채득하였다(Fig. 11).

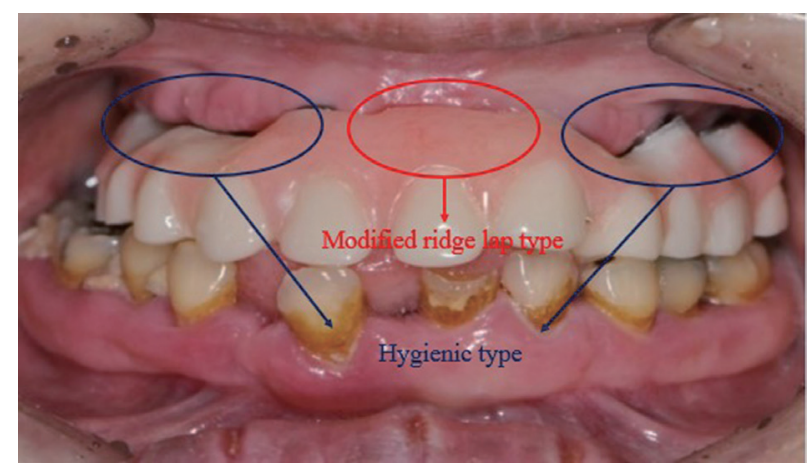

Fig. 10. Pontic area of temorary crown is adjusted to modified ridge lap type of anterior teeth and hygienic type of posterior teeth for oral hygiene control. 

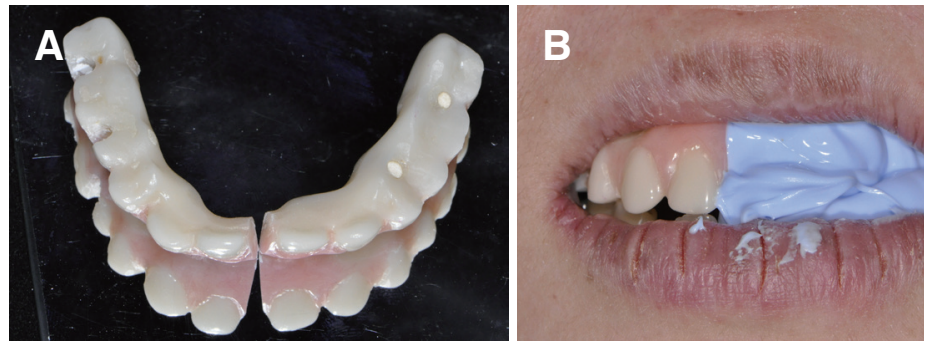

Fig. 11. Bite registration. (A) Cut temporary crown, (B) Taking bite record.

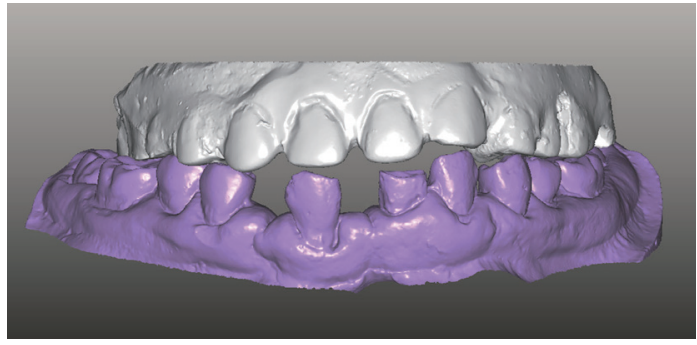

Fig. 12. Temporary crown model scan image.
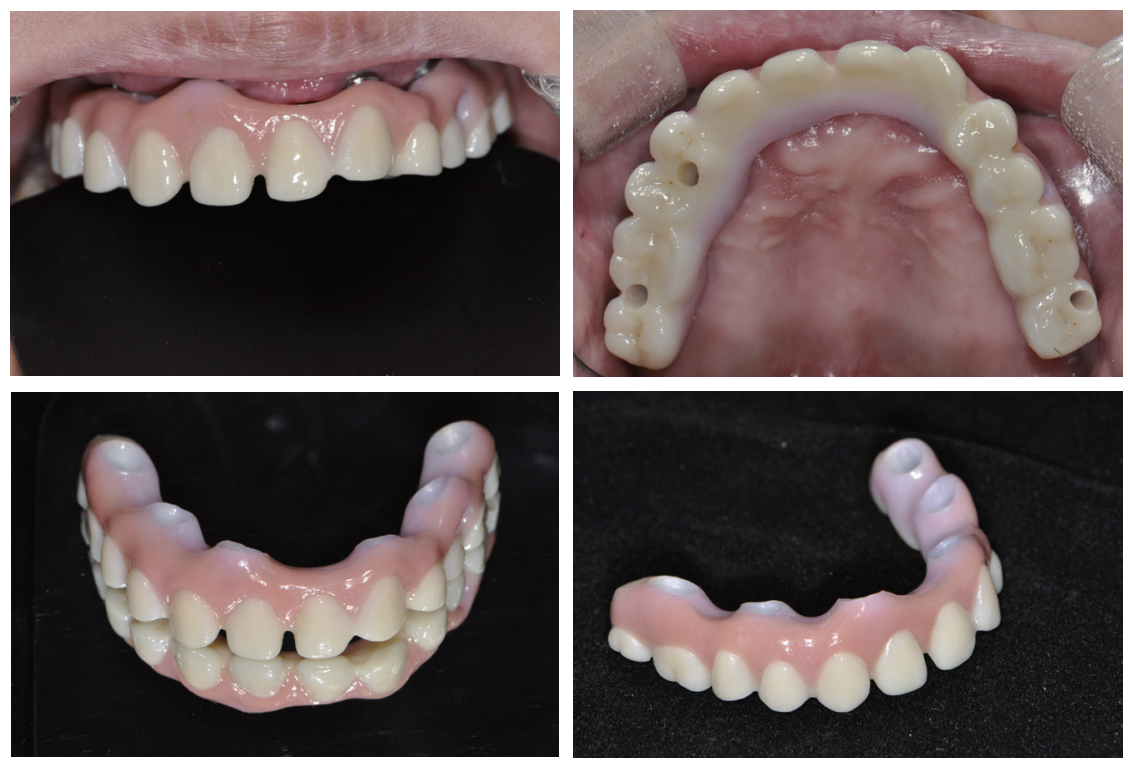

Fig. 13. Definitive prosthesis (Pontic area is adjusted to facilitate oral hygiene management).

최종 보철물은 임시치관을 모델 스캔 후 치은 부위는 cut-back 하여 지르코니아 단일구조(monolithic) 완전 도 재관(Prettau Zirconia, Zirkonzhan, Gais, Italy)으로 밀 링 제작하였다(Fig. 12). 치은 부위는 도재로 재현하였고, 보철물의 \#16,14,26 부위는 스크류 유지형, \#12,22,24 부위는 시멘트 유지형으로 임시 시멘트(Premier implant cement, Premier Products Co., Plymouth Meeting, USA) 를 이용하여 최종 보철물을 장착하였다(Fig. 13). T-scan III (T-Scan III ${ }^{\circledR}$, Tekscan Inc, South Boston, USA)를 이용하여 조화롭고 균등한 교합접촉을 부여하였다(Fig. 14). 현재 보철물 장착 후 1 년째 본원 예방치과와 협진 을 통해 구강위생관리 및 정기검진을 시행하였으며(Fig. 15), 심미적, 기능적으로 만족할만한 결과를 보였다.

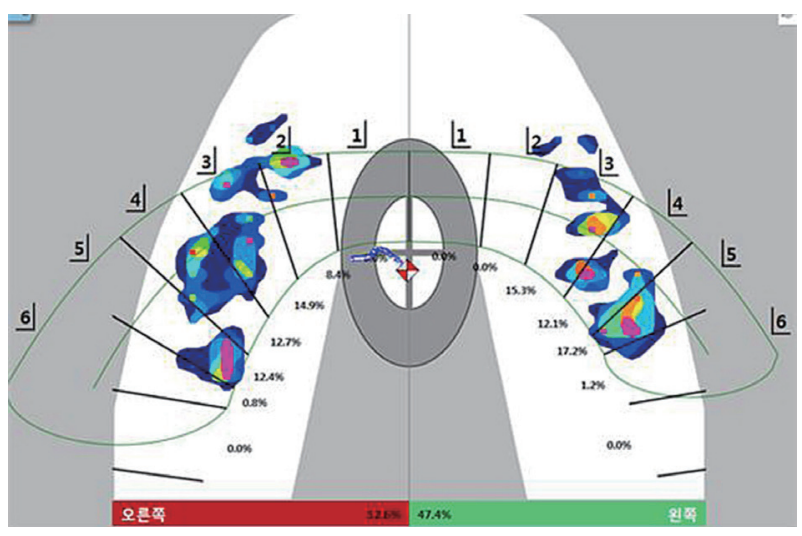

Fig. 14. Occlusal analysis using T-scan III: Equal distribution of occlusal force for whole dentition. 

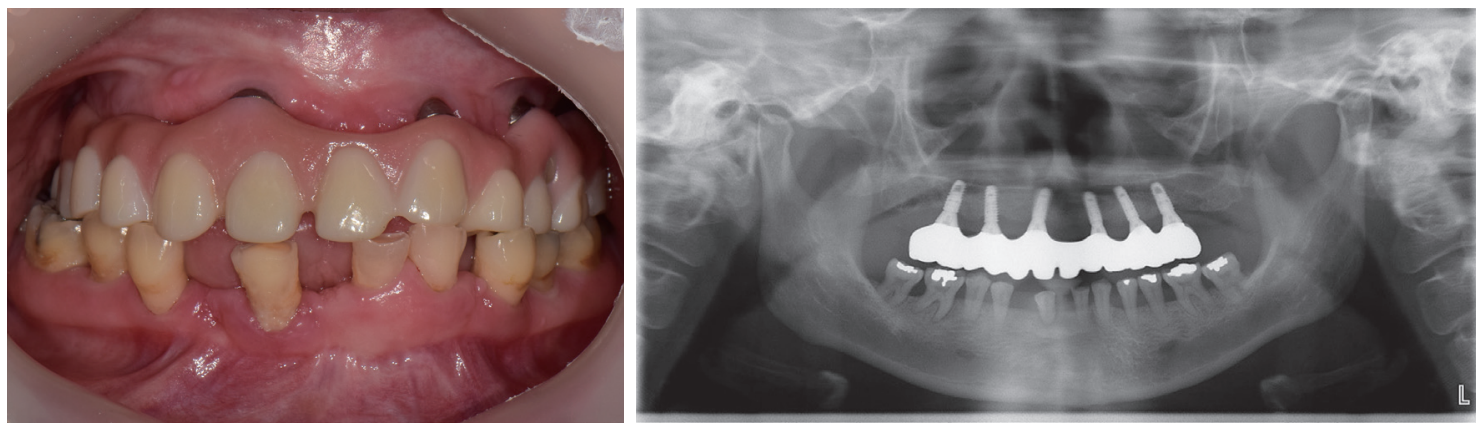

Fig. 15. Follow up check (After 1 year).

\section{고찰}

치아를 상실하여 발생한 무치악 부위를 수복하기 위 해 고려할 수 있는 치료방법으로는 총의치, 임플란트 유 지 및 지지 가철성 피개의치, 임플란트 지지 고정성 보철 이 있다. ${ }^{5}$ 총의치는 치료기간이 짧고 비용이 저렴한 장점 을 가지지만 사용하기 불편하고, 저작력이 약하며, 심리 적, 사회적으로 환자가 위축될 수 있다. 임플란트 피개의 치는 기존의 총의치에 비해 유지력과 안정성이 향상되어 저작력이 증가되지만, 임플란트 어태치먼트의 수리나 관 리비용이 추가로 드는 단점을 가진다. ${ }^{6}$ 본 증례에서 착탈 의 거부감으로 최종 치료계획은 임플란트 고정성 보철물 이 선택되었고, 이는 전통적인 가철성 총의치에 비해 보 철물의 안정과 유지력 향상, 저작효율의 증가 및 환자의 정신건강에도 도움을 주고 나아가 사회생활에 더욱 적극 적으로 대처할 수 있는 계기를 제공하기도 한다. $\mathrm{Misch}^{7}$ 는 고정성 보철물 중에서도 경조직과 연조직의 손실이 최 소일 경우에는 일반적인 고정성 보철물이 선택되고, 골과 교합면 사이의 거리가 $15 \mathrm{~mm}$ 이상인 경우 즉, 치관 높이 공간이 증가할수록 하이브리드형 보철치료 선택이 유리 하다고 하였다. 그리하여 본 증례에서는 하이브리드형 보철물을 선택하여 상실된 치아의 크기와 모양 그리고 치간유두 부위를 포함한 연조직의 일부분을 대체하였고, 하악의 잔존치열을 반영하여 상하악의 조화로운 치열을 완성할 수 있었다.

다운증후군 환자 특성상 구강위생관리 능력이 일반인 보다 떨어지기 때문에 처음 제작했던 총의치보다 치태관 리가 불리한 고정성 하이브리드 보철물로 변경하면서 구 강위생관리가 보다 용이할 수 있는 디자인을 설계하는 데 집중하였다. 먼저 임시치관 상태에서 치태관리가 용
이할 수 있도록 전치부 가공치의 순측 치은 변연은 난원 형(ovate type)이나 안장형 가공치(saddle type, ridge lap type)로 심미적인 특징을 갖지만, 설측 변연은 보다 구강 위생관리가 수월한 위생형 가공치(hygienic type)로 구성 된 변형된 치조제 피개형(Modified ridge lap)을 선택하였 고, 그에 비해 구치부는 비심미적이지만 치태 관리가 용 이한 위생형(hygienic type) 가공치로 디자인하였다(Fig. 13). ${ }^{8,9}$ 임시치관의 외형이 치태관리에 양호할 때 임시치 관을 모델스캔하여 최종보철물의 외형을 결정하였다. 최 종 보철물은 기존 하이브리드 보철물의 주된 합병증인 대합치 마모와 도재 파절을 방지하기 위해 단일관 지르 코니아를 선택하였고, 더불어 견고성과 심미성을 해결할 수 있었다..$^{10}$

현재 최종 보철물 장착 후 1 년 정기검진까지 진행하였 으며, 환자는 불편감없이 보철물을 사용하고 있다. 하이 브리드형 보철물의 경우 보철물 하방의 공간으로 치태침 착 및 음식물 저류의 문제를 고려하여 가공치부위를 수 정하였고, 그 결과 치태관리가 양호하고, 임플란트나 임 플란트 구조물에 합병증 발생시에도 보철물 제거가 가 능하여 대처가 가능할 것으로 보인다. 본 증례보고를 통 해 다운증후군 환자에게 임플란트 고정성 보철치료가 유 용한 치료계획의 한 방법임을 확인 할 수 있었다. 그러나 하악 치열을 반영하여 제작한 최종보철물은 하악 치열이 보존될 때에만 유용하여 추후 치아가 상실되었을 때 대 처가 어려울 수 있을 것으로 보인다. 이에 대비하여 치태 관리에 힘쓰도록 환자분과 보호자분께 내원시마다 구강 위생관리 교육을 시행하고 있다. 또한 지르코니아 단일 관을 이용한 하이브리드 보철물에 대한 장기적인 결과가 보고된 연구가 없기에 앞으로 지속적인 관찰이 필요할 것으로 보인다. 


\section{결론}

본 증례는 상악 무치악, 하악 부분무치증이 관찰되는 다운증후군 환자에서 상악 임플란트 하이브리드 보철물 을 제작하여 수복한 경우이다. 하악의 부분 무치증을 반 영하여 하악 인공치를 이용하여 상악 최종 보철물의 외 형을 결정하였고, 구강위생능력이 미흡한 점을 고려하여 가공치 부위를 수정하여 치태 관리가 용이하도록 최종 보철물을 제작하였다. 결과적으로 심미적, 기능적으로 만족스러운 결과를 얻을 수 있었다.

\section{ORCID}

Mi-Gyeong Kim https://orcid.org/0000-0001-9636-0761 Jae-Hoon Kim https://orcid.org/0000-0002-2807-6707

Ha-Rim Lee https://orcid.org/0000-0002-3501-3472

Eun-Sun Jang https://orcid.org/0000-0002-2596-2551

Hee-Jung Kim https://orcid.org/0000-0002-2015-1530

Gyeong-Je Lee https://orcid.org/0000-0002-3545-2280

\section{References}

1. Faulks D, Collado V, Mazille MN, Veyrune JL, Hennequin M. Masticatory dysfunction in persons with Down's syndrome. Part 1: aetiology and incidence. J Oral Rehabil 2008;35;854-62.
2. Cheng RHW, Yiu CKY, Leung WK. Oral health in individuals with down syndrome. In: Dey S. editor. Prenatal diagnosis and screening for down syndrome. London; IntechOpen; 2011. p. 59-76.

3. Oliveira AC, Paiva SM, Campos MR, Czeresnia D. Factors associated with malocclusions in children and adolescents with Down syndrome. Am J Orthod Dentofacial Orthop 2008;133:489.e1-8.

4. Desai SS, Flanagan TJ. Orthodontic considerations in individuals with Down syndrome: a case report. Angle Orthod 1999;69:85-8.

5. Rich BM, Augenbraun H. Treatment planning for the edentulous patient. J Prosthet Dent 1991;66: 804-6.

6. DeBoer J. Edentulous implants; overdenture versus fixed. J Prosthet Dent 1993;69:386-90.

7. Misch CE. Dental Implant Prosthetics. 2nd ed. St. Louis, Elsevier; 2015. p.189-94.

8. Tjan AH. A sanitary "arc-fixed partial denture": concept and technique of pontic design. J Prosthet Dent 1983;50:338-41.

9. Becker CM, Kaldahl WB. Current theories of crown contour, margin placement, and pontic design. 1981. J Prosthet Dent 2005;93:107-15.

10. Altarawneh S, Limmer B, Reside GJ, Cooper L. Dual jaw treatment of edentulism using implantsupported monolithic zirconia fixed prostheses. J Esthet Restor Dent 2015;27:63-70. 


\section{다운증후군 환자에서 임플란트 하이브리드 보철 치료 증례}

\section{김미경, 김재훈, 이하림, 장은선, 김희중, 이경제*}

조선대학교 치과대학 치과보철학교실

다운증후군 환자는 일반적으로 구강 관리에 대한 인식과 수행능력의 부족으로 구강위생상태가 불량하며, 치아 상실의 위험이 높다. 또한 작고 불규칙한 치아, 부분 무치증의 구강 내 특징으로 보철 치료에 어려움이 있다.

본 증례는 다운증후군 환자에서 상악 무치악 부위의 임플란트 하이브리드 보철 치료에 대한 케이스를 보고하고자 한다. 최종보철물의 외형은 하악 잔존치와 인공치를 조화롭게 설정하여 결정하였고, 위생관리가 용이하도록 가공치부위를 수 정하였다. 결과적으로 심미적, 기능적으로 만족스러운 결과를 얻었기에 이를 보고하고자 한다.

(구강회복응용과학지 2018;34(3):225-31)

주요어: 다운증후군; 부분 무치증; 임플란트 하이브리드 보철물; 보철물 유지관리 